\title{
Clinical use of the fibular flap
}

\author{
Utilizarea clinică a lamboului fibular
}

\author{
Iulia MURARU1 ${ }^{1}$, Dragoș MURARU ${ }^{1,2}$, Dragoș ZAMFIRESCU ${ }^{1}$, Ioan LASCĂR ${ }^{3,4}$ \\ ${ }^{1}$ Clinica Zetta, Bucureşti, România \\ ${ }^{2}$ Clinica de Chirurgie Plastică şi Microchirurgie Reconstructivă, \\ Spitalul Universitar de Urgenţă Militar Central „Dr. Carol Davila“, Bucureşti, România \\ ${ }^{3}$ Clinica de Chirurgie Plastică şi Microchirurgie Reconstructivă, \\ Spitalul Universitar de Urgenţă, Bucureşti, România \\ ^Universitatea de Medicină şi Farmacie „Carol Davila“, Bucureşti, România
}

\section{ABSTRACT}

The reconstruction of bone defects still represents a great challenge for surgeons mainly because it is aimed to properly restore the site of the defect, to maintain the motor and sensate function, and, not lastly, to recreate or maintain the aesthetics of the region. The fibular flap is a great choice for bone defect reconstruction, with a large array of clinical utilization, but insufficiently used because of its demanding technique of harvesting. The ability to transfer simultaneously bone, muscle and skin in a one-stage vascular anastomosis makes this flap even more appealing when addressing composite defects.
\end{abstract}

Keywords: fibular flap, reconstruction, bone defect

\section{REZUMAT}

Reconstrucția defectelor osoase reprezintă în continuare o mare provocare chirurgicală întrucât se dorește reconstrucția adecvată a defectului, cu menținerea funcției motorii și senzitive, dar și recrearea sau menținerea unității estetice. Lamboul fibular reprezintă o alegere excelentă pentru reconstrucția defectelor osoase, cu o largă aplicabilitate clinică, dar insuficient utilizat deoarece recoltarea acestuia este foarte dificilă. Întrucât acest lambou se poate recolta împreună $\mathrm{cu}$ țesut muscular sau cu o insulă cutanată, acest lambou devine și mai promițător atunci când se încearcă reconstrucția unor defecte mixte într-o singură etapă chirurgicală.

Cuvinte cheie: lambou fibular, reconstrucție, defecte osoase

\section{INTRODUCERE}

Defectele segmentare osoase reprezintă o provocare în practica medicală, întrucât menținerea integrității suportului osos este esențială pentru asigurarea calității vieții pacientului. Au fost studiate și folosite numeroase alternative pentru reconstrucția osoa- să având drept scop scăderea morbidității potențialei zone donatoare, precum alogrefele sau substituenții sintetici, dar toate aceste produse vin la pachet cu o serie de complicații ce includ riscul de transmitere a unor boli, infecția sau rejetul autoimun [1]. Autogrefele osoase vascularizate reprezintă varianta ideală de 
reconstrucție a defectelor osoase, dar folosirea lor ca grefe transferate liber este mult mai solicitantă ca tehnică chirurgicală [2]. Timpul operator lung, disecția extensivă și riscurile operatorii asociate fac ca această opțiune reconstructivă să fie rezervată defectelor osoase ce depășesc 6-8 cm lungime [3]. Avantajul autogrefelor osoase vascularizate este dat de faptul că ele vin cu propriul lor pat vascular și celule vii, iar vindecarea locală este asemănătoare procesului de vindecare a fracturilor osoase. Comparativ cu alogrefele, vindecarea locală este mult mai rapidă, făcându-se în aproximativ 3-5 luni [4].

\section{NOȚIUNI DE ANATOMIE}

Pediculul vascular dominant al lamboului fibular este reprezentat de artera peronieră, care este însoțită de două vene comitante [5]. Artera peronieră provine din artera tibială posterioară, de care se desprinde la 2-3 cm inferior de mușchiul popliteu. Artera peronieră, artera tibială anterioară și artera tibială posterioară reprezintă principalele trei ramuri ale arterei poplitee. În mod normal, artera peronieră nu contribuie în mod semnificativ la vascularizația gambei și a piciorului, dar, ca urmare a unor variații anatomice la nivelul arterei tibiale anterioare sau posterioare, artera peronieră poate deveni vasul dominant [6]. Acesta este motivul pentru care este absolut necesară efectuarea unei angiografii preoperator pentru evaluarea vascularizației zonei donatoare [7]. Conform clasificării Strauch și colab., există patru variații ale arterei peroniere, iar în $8 \%$ dintre cazuri artera peronieră ia locul arterei tibiale posterioare [8]. Dacă una dintre cele trei artere principale ale gambei este semnificativ redusă în diametru sau lipsește, nu trebuie ridicat lamboul de la acel picior [9]. Modificări aterosclerotice pot duce, de asemenea, la creșterea riscului de pierdere a lamboului sau complicații ischemice pe termen lung. În aceste cazuri, trebuie căutată o altă zonă donatoare. Deși au fost identificate variații ale anatomiei venoase, nu există contraindicații din acest punct de vedere [9].

Pe traiectul său, pe lângă ramurile periosteale și medulare ce vascularizează fibula, artera peronieră dă și niste ramuri perforante fasciocutanate care trec prin septul posterior pentru a vasculariza pielea. Aceste perforante sunt deosebit de importante de conservat atunci când se ridică un lambou fibular mixt osteoseptocutanat pentru acoperirea unor defecte de părți moi [10]. Vasele de sânge ce vascularizează pielea și trec prin proximitatea septului crural posterior au fost clasificate de Yoshimura în trei categorii: tipul A, care trec prin prin peronierul lung în regiunea proximală a gambei; tipul $B$, vase care trec printre mușchiul solear și mușchii peronieri și care dau ramuri musculare înainte de a asigura vascularizația pielii; tipul C, asemănătoare cu tipul B, dar care nu dau ramuri musculare [11]. Wei a descris două tipuri de perforante septocutanate: unele care traversează septul posterior pe întreaga lor lungime și altele care trec prin flexorul lung al halucelui, tibialul posterior sau mușchiul solear înainte de a ajunge în septul posterior și de a vasculariza pielea [12]. Ulterior, Wei le-a denumit pe ultimele „ramuri musculo-cutanate“. Shusterman și colab. au clasificat vasele de sânge cu un traiect intramuscular înainte de a ajunge prin septul posterior la piele drept perforante septomusculare, pentru a le deosebi de ramurile musculocutanate care ies la suprafața mușchiului înainte de a se ramifica în stratul subcutanat [13]. Atunci când este necesar sa fie recoltat un lambou care să conțină o insulă cutanată, cea mai potrivită regiune este situată la joncțiunea treimii distale cu treimea medie a gambei, de obicei la 8-12 cm proximal de gleznă, deoarece aici se găsesc frecvent perforante mari septocutanate.

Deși fibula nu este necesară pentru susținerea greutății corpului, câte un segment de câțiva $\mathrm{cm}$ trebuie conservat la capete pentru a menține stabilitatea gleznei și a proteja nervul peronier comun în porțiunea superioară a fibulei [9].

\section{UTILIZAREA CLINICĂ}

Lamboul fibular este o grefă osoasă vascularizată ce prezintă o largă aplicabilitate în reconstrucția defectelor din sfera cranio-facială, și, cu predilecție, în reconstrucția defectelor mandibulare, permițând prin lungimea sa considerabilă reconstrucția totală de mandibulă [14]. La ora actuală, el reprezintă standardul de aur în reconstrucția mandibulară [15-17].

În reconstrucția defectelor mandibulare, este foarte importantă localizarea anatomică a defectului osos. Defectele situate la nivelul porțiunii anterioare mandibulare necesită o planificare mult mai riguroasă a reconstrucției pentru restabilirea estetică și funcțională, comparativ cu defectele posterioare, întrucât această regiune este direct implicată în procesele de masticație, fonație, deglutiție, articularea cuvintelor, prin suportul pe care îl oferă limbii și musculaturii faciale. La ora actuală, este obligatorie restabilirea tuturor acestor funcții în momentul în care se pune problema reconstrucției mandibulare [18].

Din punct de vedere anatomic, mandibula este o structură osoasă în formă de "U“ care conferă înălțimea, lățimea și proiecția etajului inferior facial. La nivelul corpului și arcului mandibular, este inserată dentiția, iar ramul mandibular se articulează la nivelul bazei craniului, permițând astfel funcții importante precum vorbirea și masticația. În plus, mandibula reprezintă punctul de sprijin pentru o serie de structuri direct implicate în procesele funcționale: anterior, se 
află regiunea mentonieră, buzele și comisura orală, lateral, obrajii și mucoasa intraorală, posterior, stâlpii faringieni, iar medial, podeaua bucală și limba [19].

Datorită acestei structuri complexe a acestei regiuni, cu componente ce sunt intricate în funcții specifice regiunii oro-mandibulare, orice defect localizat în această zonă necesită o planificare preoperatorie deosebit de riguroasă în vederea menținerii unității funcțional-estetice. Ideal este ca defectul să fie înlocuit cu o structură ce mimează țesutul lipsă în ceea ce privește structura, geometria și caracteristicile tisulare $[20,21]$.

Vascularizația endosteală și periosteală robustă a fibulei permite efectuarea osteotomiilor în vederea modelării tridimensionale a lamboului pentru restabilirea structurii, dar și a funcției în zona reconstruită. Prin recoltarea lamboului fibular cu o structură compozită, este permisă acoperirea unor defecte mixte de os, mușchi și tegument [14].

La ora actuală, se folosesc tehnici computerizate de stabilire a planului preoperator în vederea obținerii unui rezultat funcțional și estetic maximal. Există numeroase programe de calculator care calculează în mod precis, pornind de la investigatiile preoperatorii paraclinice (CT și angio-CT), extensia rezecției mandibulare, lungimea lamboului ce necesită a fi recoltat și ajută la crearea unor tipare de osteotomie a fibulei, precum și la design-ul unei plăcuțe de osteosinteză individualizată pentru fiecare caz în parte [22]. Astfel, se reduce în mod considerabil durata intervenției chirurgicale și se obține o aproximare optimă a segmentelor osoase, comparativ cu metoda clasică de osteotomie, al cărei rezultat este influențat în mod direct de experiența operatorului [23]. Totuși, oricât de precise ar fi osteotomiile, un rol hotărâtor la rezultatul final îl are modul în care se poziționează neomandibula la segmentul restant [15]. Un studiu din 2019 evidențiază faptul că planning-ul preoperator asistat virtual reduce considerabil timpul de ischemie intraoperatorie, timpul total al intervenției, precum și durata totală a spitalizării [24].

Defectele mandibulare pot surveni în urma rezecțiilor oncologice și a tratamentului osteoradionecrozelor sau posttraumatic. Uneori, sunt necesare procedee complexe de reconstrucție, mai ales când sunt implicate într-un grad mai mare părțile moi [20].

Prin prisma faptului că lamboul fibular conferă o grefă osoasă rezistentă, ce poate atinge dimensiuni semnificative, cu o configurație anatomică dreaptă, acesta este adecvat și pentru reconstrucțiile defectelor osoase de la nivelul membrelor. Fibula este folosită cu succes pentru înlocuirea oaselor antebrațului și se potrivește perfect în canalul medular al humerusului, femurului sau al tibiei (vezi figurile 1, 2, 3, 4, 5 și 6) [25].

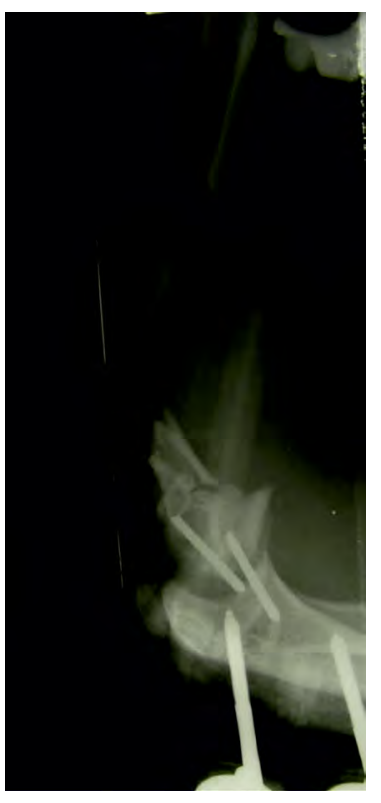

FIGURA 1. Aspect radiologic defect osos humeral

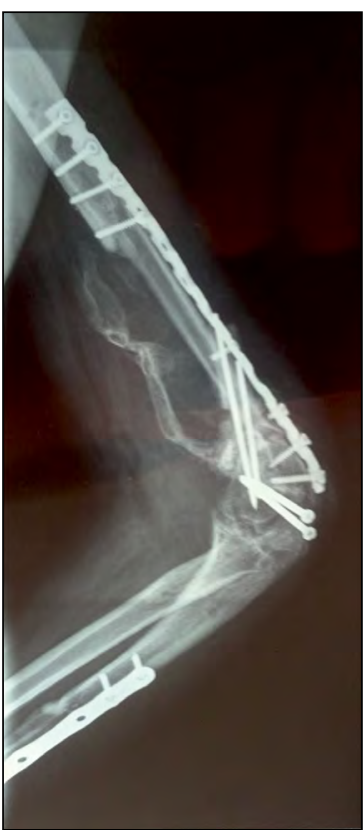

FIGURA 2. Aspect radiologic după reconstrucție defect humeral cu grefă fibulară vascularizată osteocutanată
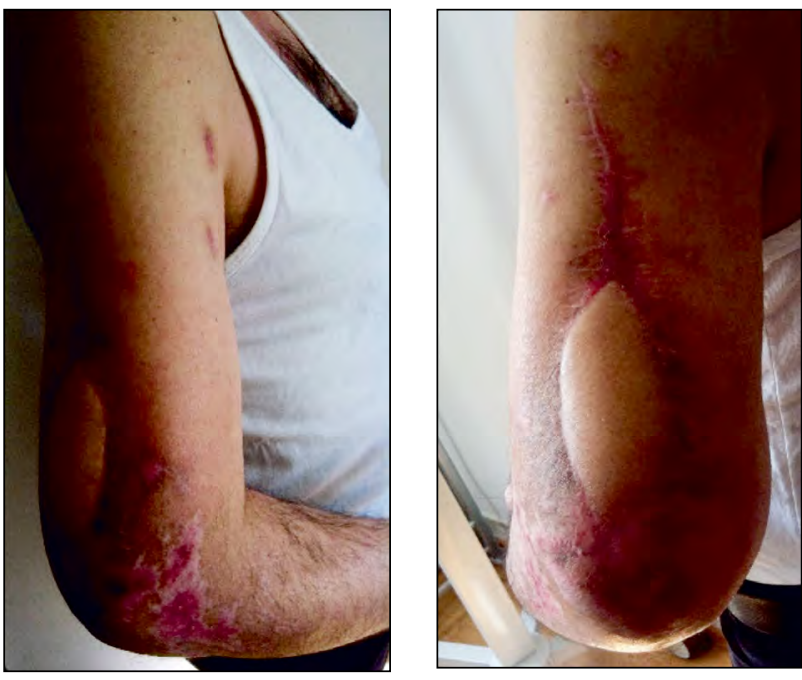

FIGURILE 3 și 4. Aspect clinic al integrării locale a lamboului osteocutanat fibular după reconstrucție humerală 

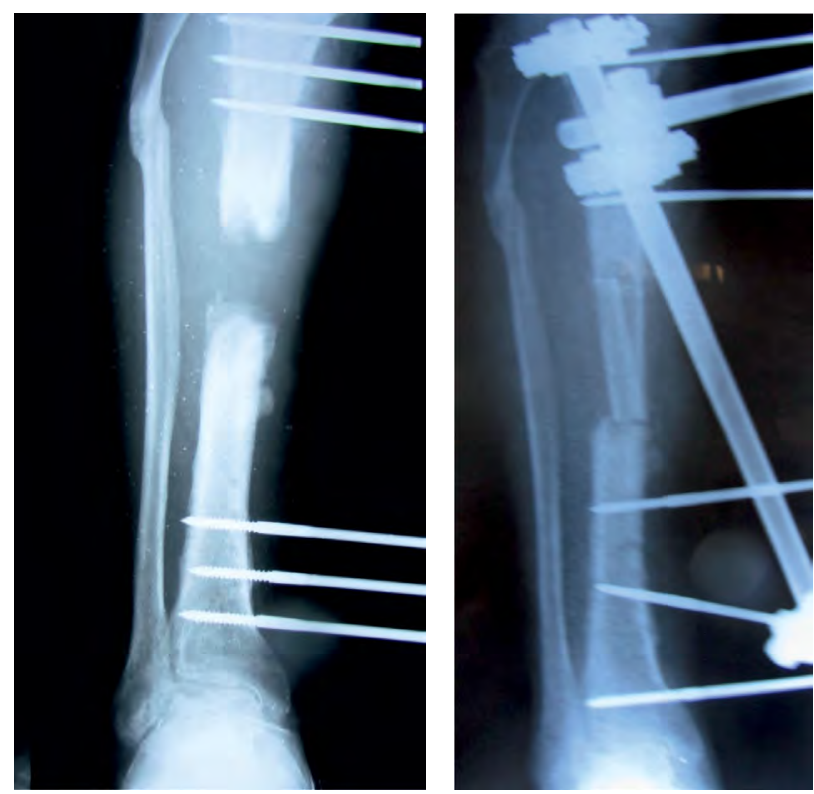

FIGURILE 5 și 6. Aspect radiologic preoperator defect osos tibial și postoperator după reconstructia cu lambou fibular transferat liber

Din cauza diferenței de diametru între fibulă și tibie sau femur, există riscul fracturilor la nivelul grefei osoase. Acest lucru se întâmplă în până la $25 \%$ dintre cazurile de reconstrucție. În timp, fibula se poate hipertrofia, mărindu-și diametrul până la 40\%-100\%, dar acest proces se petrece până în trei ani [4]. În reconstrucția defectelor femurale sau tibiale ce depășesc $6 \mathrm{~cm}$ lungime, pentru a surmonta problema diferenței de diametru, se recomandă folosirea tehnicii de tip „double-barrel“ (vezi figura 7) [14]. Această tehnică se poate aplica pentru defectele mai mici de $13 \mathrm{~cm}[26]$.

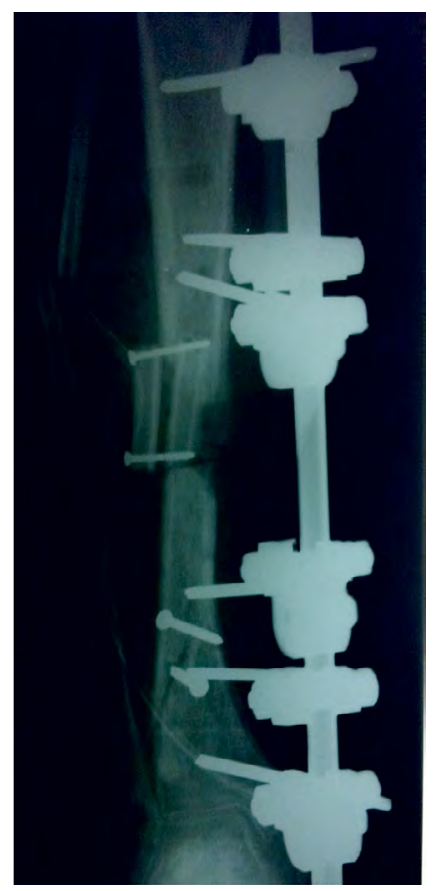

FIGURA 7. Aspect radiologic reconstrucție defect tibial cu grefă liberă fibulară poziționată după tehnica "double-barrel"
Pentru defectele localizate la nivelul piciorului ce depășesc $3,5 \mathrm{~cm}$ lungime, se indică reconstrucția cu grefă liberă vascularizată fibulară, iar pentru defectele mai mici de $3,5 \mathrm{~cm}$ se recurge, de regulă, la reconstrucția cu condil femural medial sau lambou din creasta iliacă [14].

Reconstrucția defectelor osoase cu lambou fibular după rezecții oncologice ocupă un loc important în practica medicală. Cele mai comune patologii maligne musculoscheletale sunt reprezentate de sarcomul Ewing și osteosarcomul. Pentru aceste situații, cea mai mare rată de supraviețuire este dată de descoperirea precoce și tratamentul chirurgical. Pacienții diagnosticați cu aceste afecțiuni sunt, de regulă, tineri, majoritatea cu vârsta cuprinsă între 20 și 29 de ani, la care se dorește rezecția osoasă cu conservarea membrelor pentru a nu le afecta calitatea vieții. Pentru reconstrucțiile defectelor mari rezultate după o rezecție largă, în limite de siguranță oncologică, se alege lamboul vascularizat fibular. Acesta oferă și avantajul vindecării mai rapide, permițând începerea precoce a tratatamentului oncologic neoadjuvant [27].

Capanna și colab. au descris o tehnică ce combină alogrefe structurale de mari dimensiuni cu lamboul fibular transferat liber în reconstrucția osoasă a defectelor de mari dimensiuni după rezecții oncologice. Astfel, se îmbină beneficiul rezistenței mecanice a alogrefei cu potențialul de vindecare primară a autogrefei vascularizate [4].

Pelvisul este o zonă cu o incidență de $10-15 \%$ a leziunilor maligne osoase și până la $5 \%$ a sarcoamelor, dar foarte greu de abordat terapeutic în ceea ce privește obținerea unui rezultat funcțional. În aceste cazuri, este ideal să se efectueze hemipelvectomia internă, cu salvarea membrelor, iar pentru menținerea suportului scheletic să se efectueze reconstrucția ineIului pelvin cu grefă liberă fibulară. Chang și colab. au descris rezultate bune folosind grefa fibulară cu dublă structură, această tehnică permițând facilitarea ambulației timpurii și restabilirea normală - sau aproape normală - a mersului [28].

Grefa liberă fibulară este utilizată cu succes în tratamentul chirurgical al necrozei aseptice de cap femural, pentru alungirea osoasă, reconstrucția de corp vertebral sau tratamentul pseudoartrozelor [14].

Din 1991, când Hayden și O'Leary descriu pentru prima dată lamboul osteocutanat fibular sensibilizat prin recoltarea nervului sural cutanat lateral pentru restabilirea senzației, posibilitățile de utilizare clinică a acestui lambou au primit o nouă perspectivă [10]. La doi ani după aceasta, Sadove și colab. au descris reconstrucția peniană într-o singură etapă chirurgicală prin utilizarea lamboului sensibilizat [29].

Deși au trecut mai bine de trei decenii de la introducerea lamboului fibular osteoseptocutanat de către 
Wei (în 1986), prezentând o largă aplicabilitate în microchiurgia reconstructivă, acest lambou nu este suficient de bine exploatat întrucât recoltarea acestuia necesită o vastă experiență microchirurgicală [30].

\section{CONCLUZII}

Procesul de selecție a procedeului reconstructiv adecvat în cazurile de defecte segmentale osoase sau de non-uniuni osoase este unul complicat. De regulă, se recomandă o abordare multidisciplinară ortoplastică. Întotdeauna trebuie avute în vedere obiectivele reconstructive, potențialul de reabilitare și statusul biologic al pacientului. Lamboul liber vascularizat fibular a demonstrat că este o metodă excelentă de reconstrucție într-o singură etapă a defectelor osoase complicate de diferiți factori, dar acesta necesită o înțelegere aprofundată a anatomiei regionale.

\section{BIBLIOGRAFIE}

1. Wee C, Ruter R, Schulz S. Reconstruction of extremity long bone defects with vascularized fibula bone grafts. Plast Aesthet Res. 2019;6:12.

2. Elsalanty ME, Genecov DG. Bone grafts in craniofacial surgery. Craniomaxillofac Trauma Reconstr. 2009;2(3):125-134.

3. Bishop AT, Shin AY. Vascularied Bone Grafting. Green's Operative hand surgery. Philadelphia, Elsevier, 2017;1612-1642.

4. Moran SL, Shin AY, Bishop AT. The Use of Massive Bone Allograft with Intramedullary Free Fibular Flap for Limb Salvage in a Pediatric and Adolescent Population. Plastic and Reconstructive Surgery. 2006; 118(2):413-419.

5. Sparks DS, Saleh DB, Rozen WM Hutmacher DW, Schuetz MA, Wagels M. Vascularised bone transfer: History, blood supply and contemporary problems. J Plast Reconstr Aesthet Surg. 2017;70(1):1-11.

6. Portilho PO, Leite TFO, Cardoso R, Pires LAS, Silva JG, Chagas CAA. Clinical features of a rare anatomical variation of the posterior tibial and fibular arteries. $J$ Vasc Bras. 2016;15(3):234-238.

7. Betar NM, Subramaniam SS, Borgna SC Fibula free flap with type IIIB popliteal artery branching: A case report and recommendations. Eur J Plast Surg. 2020.

8. Pototschnig H, Schaff J, Kovacs L, Biemer E, Papadopulos NA. The free osteofasciocutaneous fibula flap: Clinical applications and surgical considerations. Injury. 2013;44(3):366-369.

9. Wolff K, Hölzle F. Fibula Flap. Raising of Microvascular Flaps. Springer, 2018 159-185.

10. Urken ML. Atlas of Regional and Free Flaps for Head and Neck Reconstruction: Flap Harvest and Insetting. LWW, 2011.

11. Yoshimura M, Shimamura K, Iwai Y, Yamauchi S, Ueno T. Free vascularized fibular transplant. A new method for monitoring circulation of the grafted fibula. J Bone Joint Surg Am. 1983;65(9):12951301.
12. Wei FC, Chen HC, Chuang CC, Noordhoff MS. Fibular osteoseptocutaneous flap: anatomic study and clinical application. Plast Reconstr Surg. 1986;78(2):191-200.

13. Schusterman MA, Reece GP, Miller MJ, Harris S. The osteocutaneous free fibula flap: is the skin paddle reliable? Plast Reconstr Surg. 1992;90(5):787-798.

14. Wei FC, Mardini S. Flaps and Reconstructive Surgery. 2nd Edition, Elsevier. 2017.

15. Goormans F, Sun Y, Bila M, Schoenaers J. Accuracy of computer-assisted mandibular reconstructions with free fibula flap: Results of a single-center series. Oral Oncol. 2019:97:69-75.

16. Weitz J, Bauer FJ, Hapfelmeier A, Rohleder $\mathrm{NH}$, Wolff KD, Kesting MR. Accuracy of mandibular reconstruction by threedimensional guided vascularised fibular free flap after segmental mandibulectomy. $\mathrm{Br} \mathrm{J}$ Oral Maxillofac Surg. 2016;54(5):506-510.

17. Liu S, Tao S, Tan J, Hu X, Liu H, Li Z. Long-term follow-up of fibular graft for the reconstruction of bone defects. Medicine (Baltimore). 2018:97(40):e12605.

18. Akheel M, Tomar SS, Bhargava A. Vascularized free fibula flap for reconstruction of mandibular defects. Journal of Surgery. 2014;2(6-1):1-5.

19. Santis GD, Cordeiro PG, Chiarini. Atlas of Mandibular and Maxillary Reconstruction with the Fibula Flap A step-by-step approach. Springer. 2019.

20. Cheng MH, Huang JJ. Oral cavity, tongue, and mandibular reconstructions. Plastic Surgery. vol. Three. Elsevier. 2018;278-305.

21. Shen SY, Yu Y, Zhang WB, Liu XJ, Peng X. Angle-to-Angle Mandibular Defect Reconstruction With Fibula Flap by Using a Mandibular Fixation Device and Surgical Navigation. J Craniofac Surg. 2017; 28(6):1486-1491.

22. Shen SY, Yu Y, Zhang WB, Liu XJ, Peng X. Angle-to-Angle Mandibular Defect Reconstruction with Fibula Flap by Using a Mandibular Fixation Device and Surgical
Conflict of interest: none declared Financial support: none declared
Navigation. J Craniofac Surg. 2017; 28(6):1486-1491.

23. Zhang L, Liu Z, Li B, Yu H, Shen SG, Wang $X$. Evaluation of computer-assisted mandibular reconstruction with vascularized fibular flap compared to conventional surgery. Oral Surg Oral Med Oral Pathol Oral Radiol. 2016;121(2):139-148.

24. Powcharoen W, Yang WF, Yan Li K, Zhu W, Su YX. Computer-Assisted versus Conventional Freehand Mandibular Reconstruction with Fibula Free Flap: A Systematic Review and Meta-Analysis. Plast Reconstr Surg. 2019;144(6):14171428.

25. Malizos KN, Zalavras C, Dailiana Z, Beris A. Reconstruction of Large Skeletal Defects of the Extremities with: The Free Vascularized Fibula Graft. Reconstructive Microsurgery. Landes Bioscience. 2003;154-169.

26. Jones NF, Swartz WM, Mears DC, Jupiter JB, Grossman A. The "double barrel" free vascularized fibular bone graft. Plast Reconstr Surg. 1988;81(3):378-385.

27. Bach AD, Kopp J, Stark GB, Horch RE. The versatility of the free osteocutaneous fibula flap in the reconstruction of extremities after sarcoma resection. World J Surg Oncol. 2004:2:22.

28. Chang DW, Fortin AJ, Oates SD, Lewis VO. Reconstruction of the pelvic ring with vascularized double-strut fibular flap following internal hemipelvectomy. Plast Reconstr Surg. 2008;121(6):1993-2000.

29. Sadove RC, Sengezer M, McRoberts JW, Wells MD. One-stage total penile reconstruction with a free sensate osteocutaneous fibula flap. Plast Reconstr Surg. 1993;92(7):1314-1325.

30. Al Deek NF, Kao HK, Wei FC. The Fibula Osteoseptocutaneous Flap: Concise Review, Goal-Oriented Surgical Technique, and Tips and Tricks. Plast Reconstr Surg. 2018;142(6):913e-923e. 